\title{
Experimental and numerical study of wave-induced backfilling beneath submarine pipelines
}

Bayraktar, Deniz ; Ahmad, Joseph; Larsen, Bjarke Eltard ; Carstensen, Stefan; Fuhrman, David R.

Published in:

Coastal Engineering

Link to article, DOI:

10.1016/j.coastaleng.2016.08.010

Publication date:

2016

Document Version

Peer reviewed version

Link back to DTU Orbit

Citation (APA):

Bayraktar, D., Ahmad, J., Larsen, B. E., Carstensen, S., \& Fuhrman, D. R. (2016). Experimental and numerical study of wave-induced backfilling beneath submarine pipelines. Coastal Engineering, 118, 63-75.

https://doi.org/10.1016/j.coastaleng.2016.08.010

\section{General rights}

Copyright and moral rights for the publications made accessible in the public portal are retained by the authors and/or other copyright owners and it is a condition of accessing publications that users recognise and abide by the legal requirements associated with these rights.

- Users may download and print one copy of any publication from the public portal for the purpose of private study or research.

- You may not further distribute the material or use it for any profit-making activity or commercial gain

- You may freely distribute the URL identifying the publication in the public portal 


\title{
Experimental and numerical study of wave-induced backfilling beneath submarine pipelines
}

\author{
Deniz Bayraktar ${ }^{\mathrm{a}, \mathrm{b}}$, Joseph Ahmad ${ }^{\mathrm{a}}$, Bjarke Eltard Larsen ${ }^{\mathrm{a}}$, Stefan \\ Carstensen $^{\mathrm{a}}$, David R. Fuhrman ${ }^{\mathrm{a}, *}$ \\ ${ }^{a}$ Technical University of Denmark, Department of Mechanical Engineering, DK-2800 \\ Kgs. Lyngby, Denmark \\ ${ }^{b}$ Istanbul Technical University, Faculty of Naval Architecture and Ocean Engineering, \\ 34469 Istanbul, Turkey
}

\begin{abstract}
This paper presents results of complementary experimental and numerical studies involving wave-induced backfilling of current-generated scour holes beneath submarine pipelines. The laboratory experiments are conducted in a wave-plus-current flume, utilizing Laser Doppler Anemometry to measure velocities, synchronized flow visualizations using digital image technology, along with live-bed scour and backfilling measurements. Each experiment is based on a two-stage process: (1) initial scour induced by a pure current, followed by: (2) backfilling induced by pure waves (either regular or irregular). The time series of scour depths are closely monitored through video recordings. Systematic analysis of these has resulted in a closed form expression for the backfilling time scale, which is demonstrated to be a full order of magnitude greater than the well-known time scale of scour (with both governed primarily by the Shields parameter). The developed expression is strictly valid for the current-to-wave backfilling scenarios considered, while likely serving as an upper limit for more general wave-induced backfilling circumstances. The experiments are complemented by similar backfilling simulations utilizing a fully-coupled hydrodynamic and morphodynamic CFD model. The numerical simulations demonstrate the ability of the model to predict backfilling towards expected equilibrium scour depths based on the new wave climate, with time scales reasonably in line with experimental expectations.
\end{abstract}

Keywords: Scour, Backfilling, Pipelines, Sediment transport, Time scale,

\footnotetext{
* Corresponding author

Email address: drf@mek.dtu.dk (David R. Fuhrman)
} 
Steady current, Waves

\section{Introduction}

Submarine pipelines are extensively studied due to their importance in coastal and offshore engineering. They are commonly used to transport water, waste water, oil, natural gas and other hydrocarbons across marine environments. Considering the often-hazardous contents carried, the failure of a submarine pipeline may have catastrophic effects on the environment. Therefore, the integrity of the submarine pipelines is quite important. As a submarine pipeline is exposed to direct flow action, scour can develop around the pipe. This leads to suspended free spans of the pipeline which in turn increase stress and structural fatigue.

To improve the understanding of local scour developed due to current and/or waves, scour-related processes have often been studied by means of laboratory experiments (e.g. Sumer and Fredsøe, 1990; Fredsøe et al., 1992; Zhang et al., 2016). In addition to extensive laboratory experiments involving scour, several numerical models capable of predicting the scour evolution beneath pipelines induced by currents (e.g. Brørs, 1999; Zanganeh et al., 2012; Larsen et al., 2016), waves (e.g. Liang and Cheng, 2005; Kazeminezhad et al., 2012; Fuhrman et al., 2014), or their combination (Larsen et al., 2016) have also been developed and applied.

Most studies in the literature cover the scour process of submarine pipelines with a fixed wave or current climate, starting from a zero-scour initial bed profile (or for numerical models, a small initial scour depth). However, from an engineering point of view, it is also important to understand the scour profile development under changing wave and/or current climates. In such circumstances, the local weather and wave conditions could change over time, such as a transition from a strong wave climate to a mild wave climate or e.g. strong tidal currents to waves alone. While the time scales of scour processes are well-known (e.g. Fredsøe et al., 1992), there is a general lack of data in the literature concerning the related time scales of backfilling processes. This presently limits the development of engineering models capable of predicting scour depth evolution beneath pipelines over long temporal durations, potentially involving changing wave, tidal current, and weather conditions. Fredsøe et al. (1992) investigated wave-induced backfilling of wave-generated scour holes experimentally for a submarine pipeline for a limited number of test cases. Numerical studies also investigating scour as well as backfilling, due to changes in wave climate have 
likewise been conducted by Fuhrman et al. (2014). Zhang et al. (2016) also considered several experiments involving time varying flow conditions, including two cases involving the time evolution of backfilling beneath a submarine pipeline. Leckie et al. (2016) likewise studied the times scale of sedimentation around pipelines (i.e. involving the accumulation of sediment adjacent to a pipeline). Also relatedly, Sumer et al. (2013) investigated the 3D backfilling of scour holes around a monopile.

Through complementary experimental and numerical efforts, the present paper aims to make a significant contribution to the overall understanding of backfilling processes beneath submarine pipelines. For this purpose, we aim to simplify the backfilling process to its most elementary form: purewave backfilling of current-generated scour holes (i.e. so-called current-towave backfilling scenarios). For simplicity fixed pipelines will be considered, hence any complicating effects e.g. of a pipeline sagging into scoured regions will not be accounted for. Through analysis of the scour depth time series, we aim to provide the first systematic quantification of the backfilling time scale, appropriate for engineering use.

The present paper is organized as follows: The experimental study is discussed in $\S 2$ which describes the wave-plus-current flume, details of the velocity measurements done with Laser Doppler Anemometry (LDA), test conditions, as well as systematic analysis of the results in terms of the most important governing parameters. Subsequent numerical simulations are then described in $\S 3$, the results of which will be directly compared with the most important experimental findings herein. Finally, conclusions are given in $\S 4$.

\section{Experimental Study}

\subsection{Experimental set-up}

The experiments have been conducted in a wave-plus-current flume which is $26.5 \mathrm{~m}$ in length and $0.6 \mathrm{~m}$ in width, equipped with an Active Wave Absorption Control System (AWACS) and DHI Wave Synthesizer 2.40 (e.g Schäffer et al. (1994)). During the generation of the desired incident waves, this system absorbs the reflected waves.

A sediment section in the form of a sand pit with two ramps at the two ends was built in the flume. The ramp was made of crushed stones. The sand pit was $0.6 \mathrm{~m}$ wide and $0.15 \mathrm{~m}$ deep and $8.5 \mathrm{~m}$ long. A pipeline having diameter $D=3 \mathrm{~cm}$ was mounted horizontally along the width of the flume directly on the sediment bed. The median grain size of the sediment corresponds to $d=0.18 \mathrm{~mm}$, with the relative density of the sand being 
$s=2.65$. The position of the pipeline and other details are shown in the schematic view of the experimental set-up in Fig. 1.

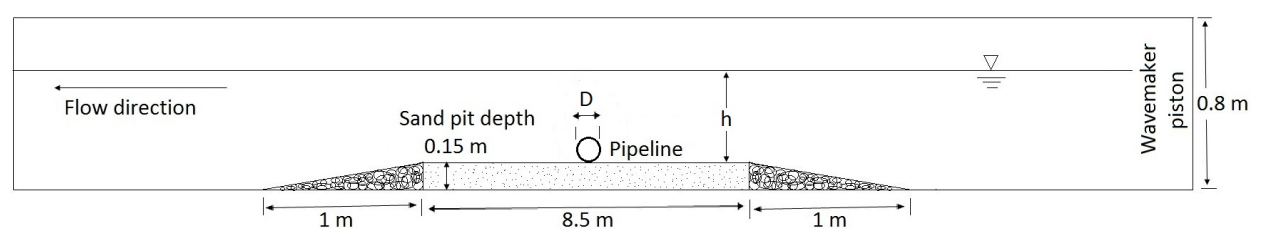

(a) Section view of the flume

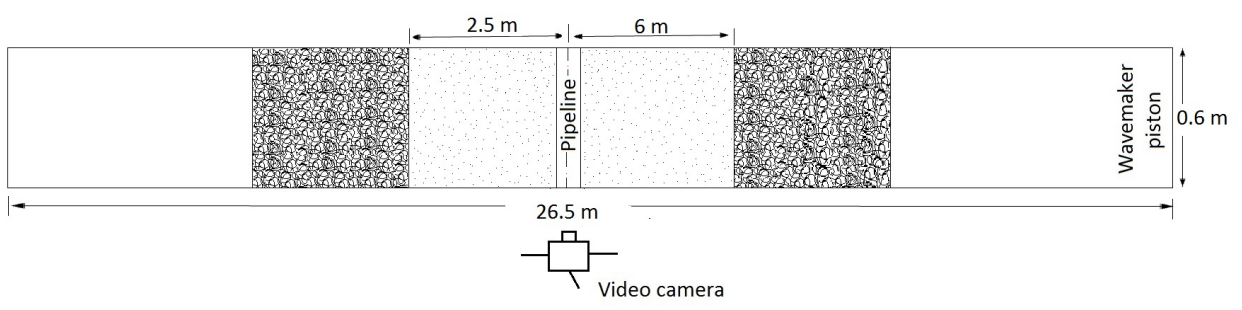

(b) Plan view of the flume

Figure 1: A schematic view of the experimental set-up.

The water depth has been maintained constant as $h=40 \mathrm{~cm}$ at the sand pit section except for a single case (test R4, to be presented in what follows). For this special case, the water depth was $h=35 \mathrm{~cm}$ at the sand pit section in order to maintain the desired characteristics. The details of this case as well as the other test conditions are given in Tables 1 (regular waves) and 2 (irregular waves). The origin $(x, y)=(0,0)$ is taken as the bottom of the pipeline.

The orbital velocity of the water particles at the bed has been measured using a two-component Dantec Dynamics LDA system (only the green component was used to measure horizontal particle velocities). The measurements have been conducted in forward scatter mode with a photo detector placed on the other side of the flume's glass wall. The system was equipped with a 55N10 frequency shifter and a 55N20 frequency tracker. The velocity measurements have been made in the absence of the pipeline, as they are intended to represent the far field. The vertical measurement point was taken as $y=D / 2$ (corresponding to the center of the pipeline) and was at a position $30 \mathrm{~cm}$ from the side wall i.e. at the center of the tank. 


\subsection{Results}

\subsubsection{Velocity measurements}

The orbital velocities measured with LDA are used to estimate KeuleganCarpenter $(K C)$ numbers and Shields parameters $(\theta)$, which are expected to be the main parameters governing the wave-induced backfilling process. The Keulegan-Carpenter number is defined as

$$
K C=\frac{U_{m} T_{w}}{D},
$$

where $U_{m}$ defines the magnitude of the the near-bed orbital velocity and $T_{w}$ is the wave period. The Shields parameter is

$$
\theta=\frac{U_{f m}^{2}}{g(s-1) d},
$$

where $U_{f m}$ is the maximum friction velocity and $g=9.81 \mathrm{~m}^{2} / \mathrm{s}$ is gravitational acceleration. The $U_{m}$ values given in Tables 1 and 2 are calculated from the spectrum function of the measured horizontal velocity, $U$, as explained by Sumer and Fredsøe (2002) with

$$
U_{m}=\sqrt{2} \sigma_{U},
$$

where $\sigma_{U}$ is the standard deviation of the measured orbital velocity. Please note that Eq. (3) becomes identical to the maximum value of the bottom orbital velocity in the case of small-amplitude (sinusoidal) waves.

Similarly, the undisturbed friction velocities, $U_{f m}$, given in Tables 1 and 2 are calculated according to:

$$
U_{f m}=\sqrt{\frac{f_{w}}{2}} U_{m}
$$

where $f_{w}$ is the wave friction factor. The $f_{w}$ values are taken as the maximum of laminar, flaminar, smooth-turbulent, $f_{w}^{\text {smooth }}$ and rough-turbulent, $f_{w}^{\text {rough }}$ wave friction factors. Here the laminar wave friction factor is calculated theoretically as

$$
f_{w}^{l a m i n a r}=\frac{2}{\sqrt{R e}},
$$

where the Reynolds number is $R e=U_{m} a / \nu, a=U_{m} T /(2 \pi)$ is the amplitude of the orbital particle motion, and the water kinematic viscosity has been taken as $\nu=10^{-6} \mathrm{~m}^{2} / \mathrm{s}$. The smooth-turbulent wave friction factor is calculated from the expression of Fredsøe and Deigaard (1992):

$$
f_{w}^{s m o o t h}=0.035 R e^{-0.16} .
$$


Finally, the rough-turbulent wave friction factor is calculated as in Fuhrman et al. (2013):

$$
f_{w}^{\text {rough }}=\exp \left(5.5\left(\frac{a}{k_{s}}\right)^{-0.16}-6.7\right),
$$

where Nikuradse's equivalent sand roughness is taken as $k_{s}=2.5 d$.

As stated previously, each experiment has been based on a two-stage process: (1) initial scour induced by a pure current, followed by: (2) backfilling induced by pure waves. The steady current was introduced via a recirculating pump, and was kept constant (for approximately 30-40 minutes) with a cross-sectional velocity of $V=0.48 \mathrm{~m} / \mathrm{s}$ until an initial equilibrium scour depth, $S_{0}$, was reached. Then, the current was stopped and waves were introduced to initiate the backfilling process, which were maintained until a new equilibrium scour depth, $S_{f}$, was reached. The time at which waves were introduced will be denoted as $t=0$. For the backfilling process both

Table 1: Summary of test conditions and results for experiments involving regular waves (R).

\begin{tabular}{cccccccccc}
\hline Test & $\begin{array}{c}H \\
(\mathrm{~cm})\end{array}$ & $\begin{array}{c}T_{w} \\
(\mathrm{~s})\end{array}$ & $\begin{array}{c}U_{m} \\
(\mathrm{~cm} / \mathrm{s})\end{array}$ & $\begin{array}{c}U_{f m} \\
(\mathrm{~cm} / \mathrm{s})\end{array}$ & $K C$ & $\theta$ & $S_{0} / D$ & $S_{f} / D$ & $T_{b}^{*}$ \\
\hline $\mathrm{R} 1$ & 6.8 & 1.5 & 14.0 & 1.7 & 7.0 & 0.098 & 0.424 & 0.260 & 21.9 \\
$\mathrm{R} 2$ & 7.5 & 1.2 & 14.1 & 1.8 & 5.6 & 0.111 & 0.529 & 0.240 & 23.1 \\
$\mathrm{R} 3$ & 10.6 & 1.0 & 13.4 & 1.9 & 4.7 & 0.119 & 0.530 & 0.229 & 25.0 \\
$\mathrm{R} 4$ & 6.5 & 0.9 & 14.0 & 2.0 & 4.6 & 0.138 & 0.657 & 0.320 & 8.7 \\
$\mathrm{R} 5$ & 7.5 & 2.4 & 18.8 & 1.7 & 14.9 & 0.105 & 0.540 & 0.330 & 3.9 \\
$\mathrm{R} 6$ & 5.6 & 1.9 & 16.6 & 1.7 & 10.4 & 0.105 & 0.556 & 0.293 & 14.8 \\
$\mathrm{R} 7$ & 7.0 & 1.6 & 16.0 & 1.8 & 8.6 & 0.108 & 0.618 & 0.330 & 8.0 \\
$\mathrm{R} 8$ & 9.6 & 1.4 & 17.4 & 1.9 & 8.4 & 0.125 & 0.518 & 0.290 & 5.4 \\
$\mathrm{R} 9$ & 13.0 & 1.2 & 24.6 & 2.4 & 9.7 & 0.195 & 0.567 & 0.290 & 3.5 \\
$\mathrm{R} 10$ & 5.7 & 3.1 & 18.4 & 1.6 & 19.2 & 0.09 & 0.770 & 0.438 & 44.6 \\
$\mathrm{R} 11$ & 7.5 & 2.4 & 16.1 & 1.6 & 13.2 & 0.089 & 0.620 & 0.363 & 55.9 \\
$\mathrm{R} 12$ & 9.8 & 2.1 & 19.8 & 1.9 & 14.2 & 0.118 & 0.690 & 0.344 & 9.2 \\
$\mathrm{R} 13$ & 8.6 & 3.6 & 19.1 & 1.6 & 23.2 & 0.087 & 0.678 & 0.376 & 4.5 \\
$\mathrm{R} 14$ & 6.0 & 3.0 & 24.8 & 1.9 & 24.8 & 0.125 & 0.596 & 0.430 & 12.0 \\
$\mathrm{R} 15$ & 10.9 & 2.6 & 18.0 & 1.7 & 15.5 & 0.097 & 0.600 & 0.340 & 7.5 \\
$\mathrm{R} 16$ & 11.4 & 2 & 24.9 & 2.1 & 16.4 & 0.152 & 0.733 & 0.370 & 3.9 \\
\hline
\end{tabular}

regular and irregular waves have been used during the experiments. The waves were produced by a piston-type wave generator making use of linear 
Table 2: Summary of test conditions and results for experiments involving irregular waves (IR).

\begin{tabular}{cccccccccc}
\hline Test & $\begin{array}{c}H_{m 0} \\
(\mathrm{~cm})\end{array}$ & $\begin{array}{c}T_{p} \\
(\mathrm{~s})\end{array}$ & $\begin{array}{c}U_{m} \\
(\mathrm{~cm} / \mathrm{s})\end{array}$ & $\begin{array}{c}U_{f m} \\
(\mathrm{~cm} / \mathrm{s})\end{array}$ & $K C$ & $\theta$ & $S_{0} / D$ & $S_{f} / D$ & $T_{b}^{*}$ \\
\hline IR1 & 7.6 & 2.4 & 9.7 & 1.2 & 7.7 & 0.054 & 0.630 & 0.300 & 36.3 \\
IR2 & 6.7 & 1.9 & 8.3 & 1.2 & 5.2 & 0.052 & 0.600 & 0.240 & 32.7 \\
IR3 & 7.8 & 1.6 & 13.4 & 1.6 & 7.2 & 0.090 & 0.610 & 0.270 & 17.2 \\
IR4 & 10.0 & 1.4 & 15.9 & 1.8 & 7.6 & 0.114 & 0.600 & 0.276 & 10.2 \\
IR5 & 6.6 & 3.1 & 132 & 1.4 & 13.7 & 0.064 & 0.687 & 0.370 & 18.5 \\
IR6 & 7.1 & 2.5 & 12.6 & 1.4 & 10.4 & 0.069 & 0.708 & 0.340 & 41.0 \\
IR7 & 8.0 & 2.1 & 14.1 & 1.6 & 10.0 & 0.083 & 0.696 & 0.340 & 18.7 \\
IR8 & 9.3 & 1.9 & 16.6 & 1.7 & 10.4 & 0.104 & 0.590 & 0.280 & 11.4 \\
IR9 & 12.4 & 1.6 & 20.1 & 2.0 & 10.5 & 0.139 & 0.670 & 0.350 & 11.1 \\
IR10 & 6.1 & 3.8 & 12.4 & 1.3 & 15.9 & 0.055 & 0.746 & 0.360 & 23.0 \\
IR11 & 7.7 & 3.0 & 16.4 & 1.5 & 16.4 & 0.082 & 0.750 & 0.370 & 19.1 \\
IR12 & 8.6 & 2.6 & 14.7 & 1.5 & 12.4 & 0.077 & 0.578 & 0.352 & 16.3 \\
IR13 & 9.9 & 2.3 & 16.3 & 1.6 & 12.5 & 0.093 & 0.646 & 0.374 & 19.4 \\
IR14 & 10.9 & 2 & 17.7 & 1.8 & 11.7 & 0.108 & 0.660 & 0.366 & 21.6 \\
\hline
\end{tabular}

wave maker theory. Considering the irregular waves, a standard JONSWAP spectrum was used as the control to produce a wave generator displacement signal. This spectrum is utilized to generate irregular waves similar to other studies (e.g Kozakiewicz et al. (1994), Sumer and Fredsøe (2000), Sumer et al. (2013)). Wave gauges, whose measuring principle is based on the electric conductivity of two rods submerged in water, were used to measure the surface elevations from which wave heights $H$ (for regular waves) or significant wave heights $H_{m 0}$ (for irregular waves) were obtained. Input wave period values $T_{w}$ (for regular waves) and $T_{p}$ (peak periods for irregular waves) for each experiment are used directly for characterizing the individual experiments. The test conditions for the backfilling experiments are given in Tables 1 and 2, again describing both use of regular and irregular waves, respectively. Note that, with the focus on backfilling, the present experiments have been designed to focus on relatively low values of $K C<25$ i.e. wave conditions likely to result in backfilling rather than scour (as equilibrium scour depths generally increase with $K C$ ). 


\subsubsection{Scour and backfilling time series}

The scour and backfilling processes have been recorded by a video camera which was placed outside the glass wall of the flume, in line with the pipeline. Through analysis of the video recordings, the time series of scour depth beneath the pipeline center for each case has been obtained. In Figures 2 and 3 , the time series of the dimensionless scour depth $S / D$ for the backfilling experiments induced by both regular and irregular waves are given, respectively. Here, the dots represent the measurements obtained via processing of the video recordings while the line plots are based on an exponential time function adopted similarly by Sumer et al. (2013):

$$
S(t)=S_{f}+\left(S_{0}-S_{f}\right) \exp \left(-\frac{t}{T_{b}}\right)
$$

where $S_{0}$ is again the initial scour depth at the beginning of the backfilling, and $S_{f}$ is again the equilibrium scour depth reached at the end of the backfilling process. It is observed that after sufficient time, the experimental backfilling curves eventually approach a new equilibrium. It is emphasized, however, that this appears to be dynamic (characterized by the fluctuations due to local and temporary adjustments that occur in the profile) rather than static. Note that similar dynamic equilibria were apparent in the numerical simulations of Fuhrman et al. (2014) and Larsen et al. (2016).

The (dimensional) backfilling time scale, $T_{b}$, has been calculated via integration, as suggested by Fuhrman et al. (2014):

$$
T_{b}=\int_{0}^{\infty} \frac{S-S_{f}}{S_{0}-S_{f}} d t .
$$

By substituting the results of this integration into Eq. (8), the line plots shown in Figures 2 and 3 are obtained for each experiment. As seen from Figures 2 and 3, Eq. (8) provides a reasonable (if idealized) description of the backfilling series for most of the cases. The resulting time scales are non-dimensionalized, as suggested by Sumer and Fredsøe (2002), according to:

$$
T_{b}^{*}=\frac{\sqrt{g(s-1) d^{3}}}{D^{2}} T_{b}
$$

The resulting values are also listed in Tables 1 and 2. For completeness,

note also that the scour process (when it was recorded) is also shown on Figures 2 and 3 at negative $t$. 

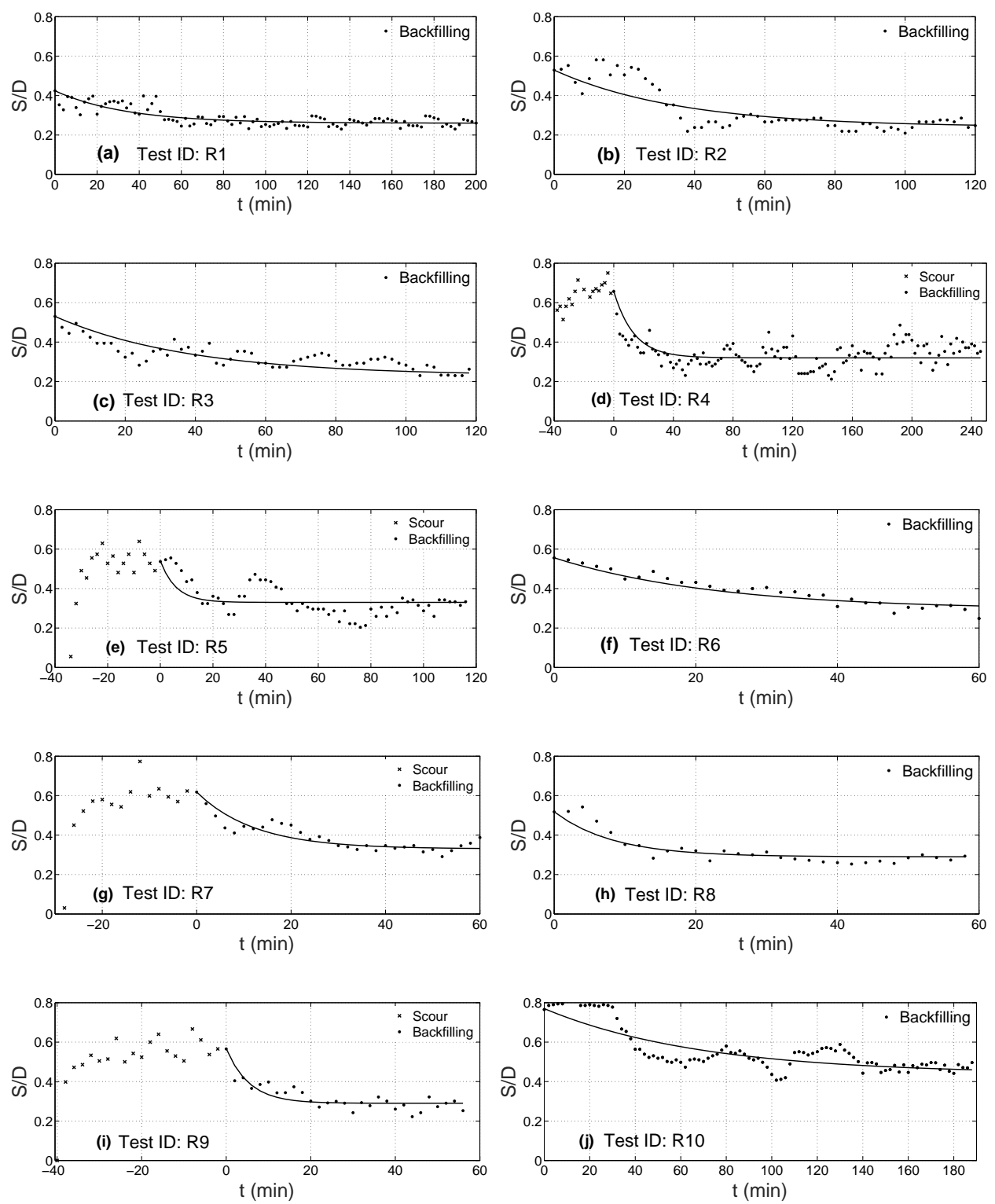

Figure 2: Time series of scour depths where scour is initially induced by a current $(t<0$, when measured), followed by backfilling induced by regular waves $(t \geq 0)$. 

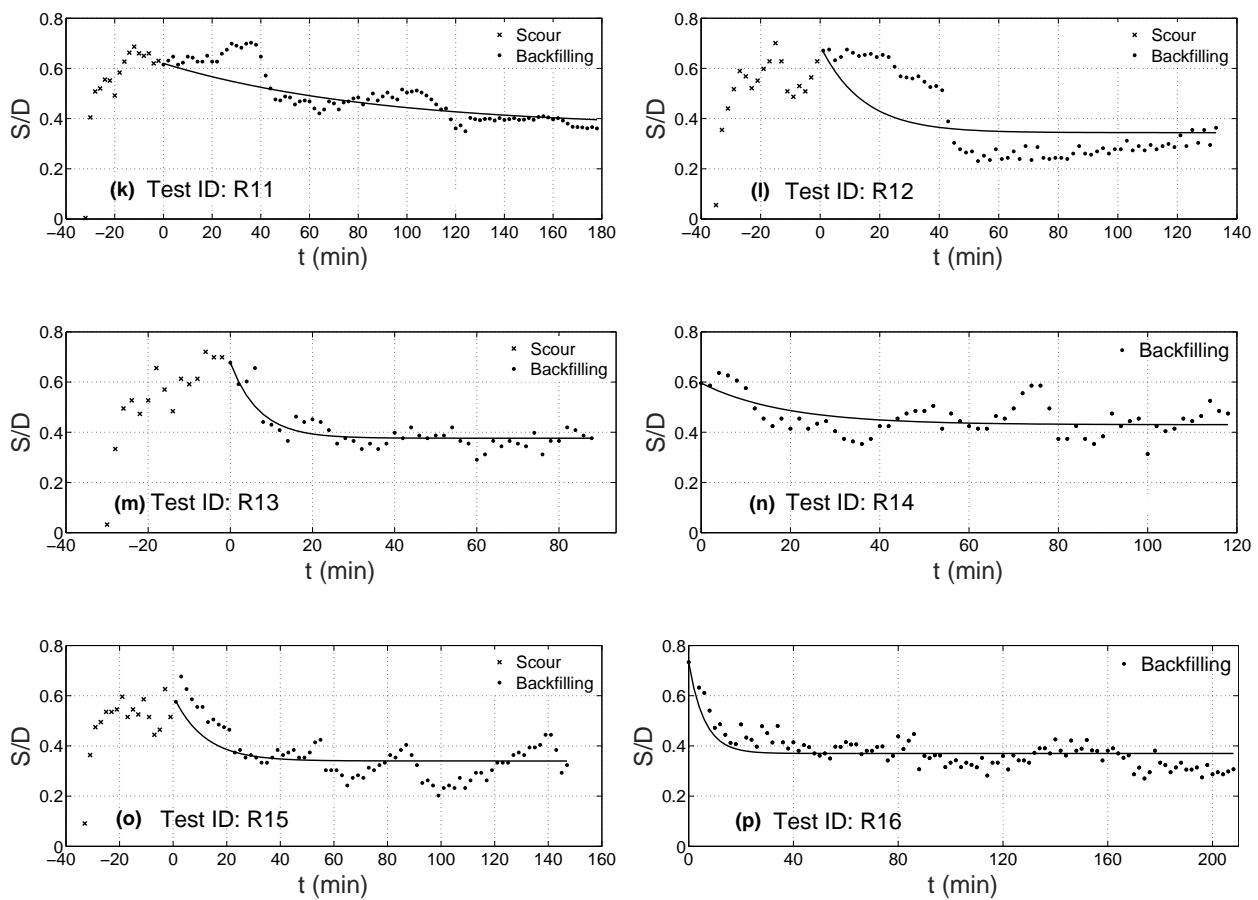

Figure 2: (contined) Time series of scour depths where scour is initially induced by a current $(t<0$, when measured), followed by backfilling induced by regular waves $(t \geq 0)$. 

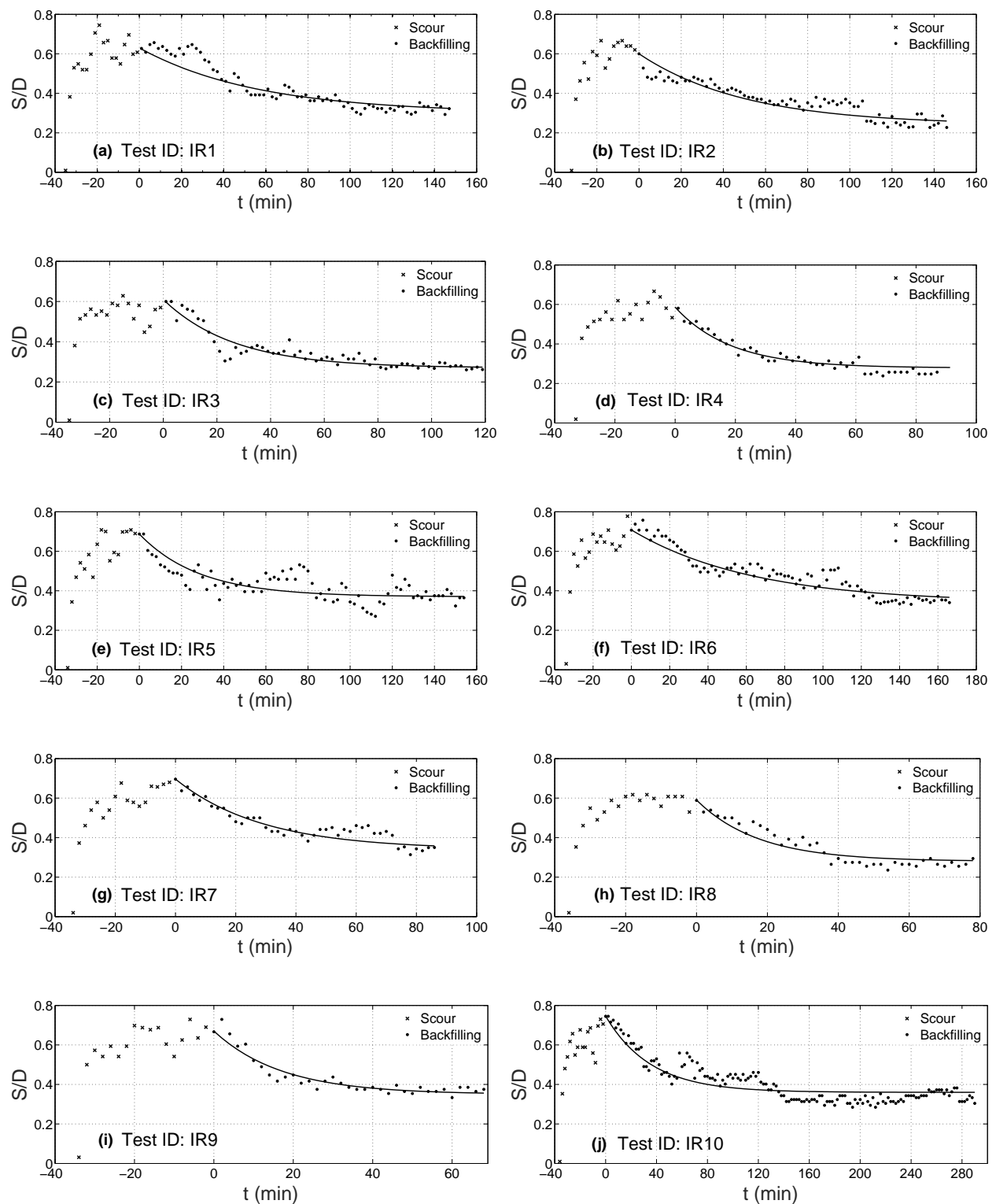

Figure 3: Time series of scour depths where scour is initially induced by a current $(t<0$, when measured), followed by backfilling induced by irregular waves $(t \geq 0)$. 

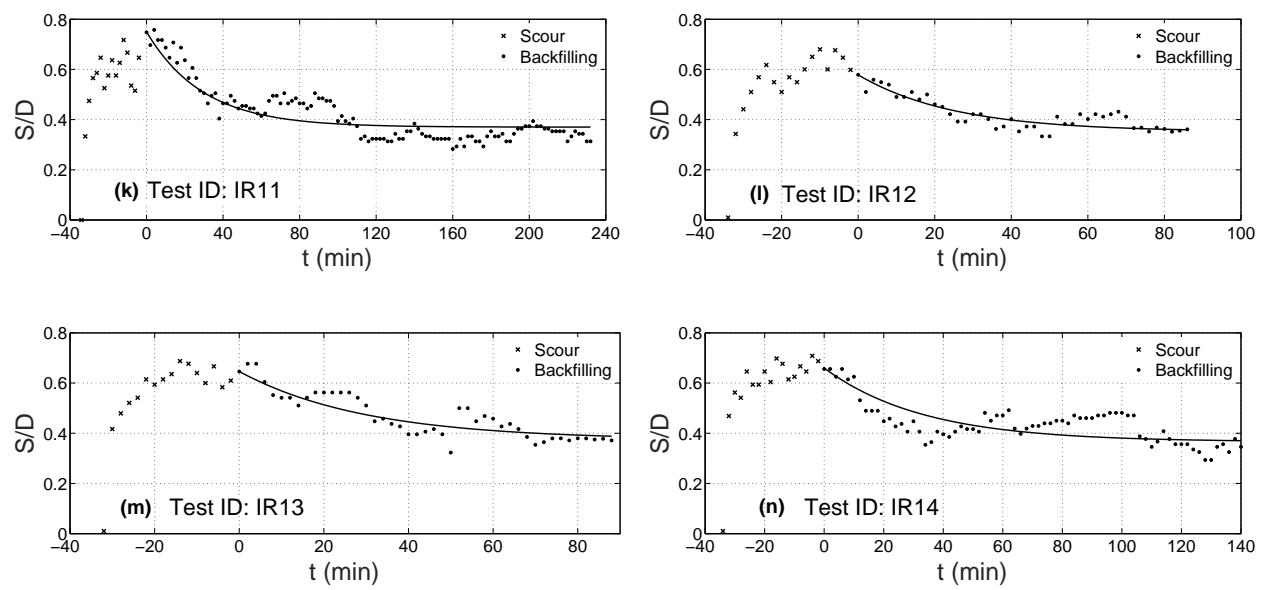

Figure 3: (continued) Time series of scour depths where scour is initially induced by a current $(t<0$, when measured), followed by backfilling induced by irregular waves $(t \geq 0)$.

As a further demonstration of the initiated two-stage (scour followed by backfilling) process, bed profiles based on video recordings made during case R9 $(K C=9.7$ and $\theta=0.195)$, are depicted at selected stages in Figure 4. Figure 4 (upper left) depicts the current-induced equilibrium scour hole in the near vicinity of the pipe at $t=0$, with the profile approximated as the dashed red line. Similarly, Figure 4 (upper right) depicts the new equilibrium scour profile (approximated as the full blue line) that has developed under wave-induced backfilling, corresponding to $t=60 \mathrm{~min}$. To ease comparison, the dashed red and full blue lines from these plots are additionally combined onto Figure 4 (bottom). This sub-plot hence depicts the scour profile at both the beginning and end of the backfilling process detailed in Figure 2(i), and clearly illustrates a typical amount of backfilling (in this case going from $S_{0} / D=0.57$ to $S_{f} / D=0.29$ ) observed around the pipeline following introduction of the wave climate. 

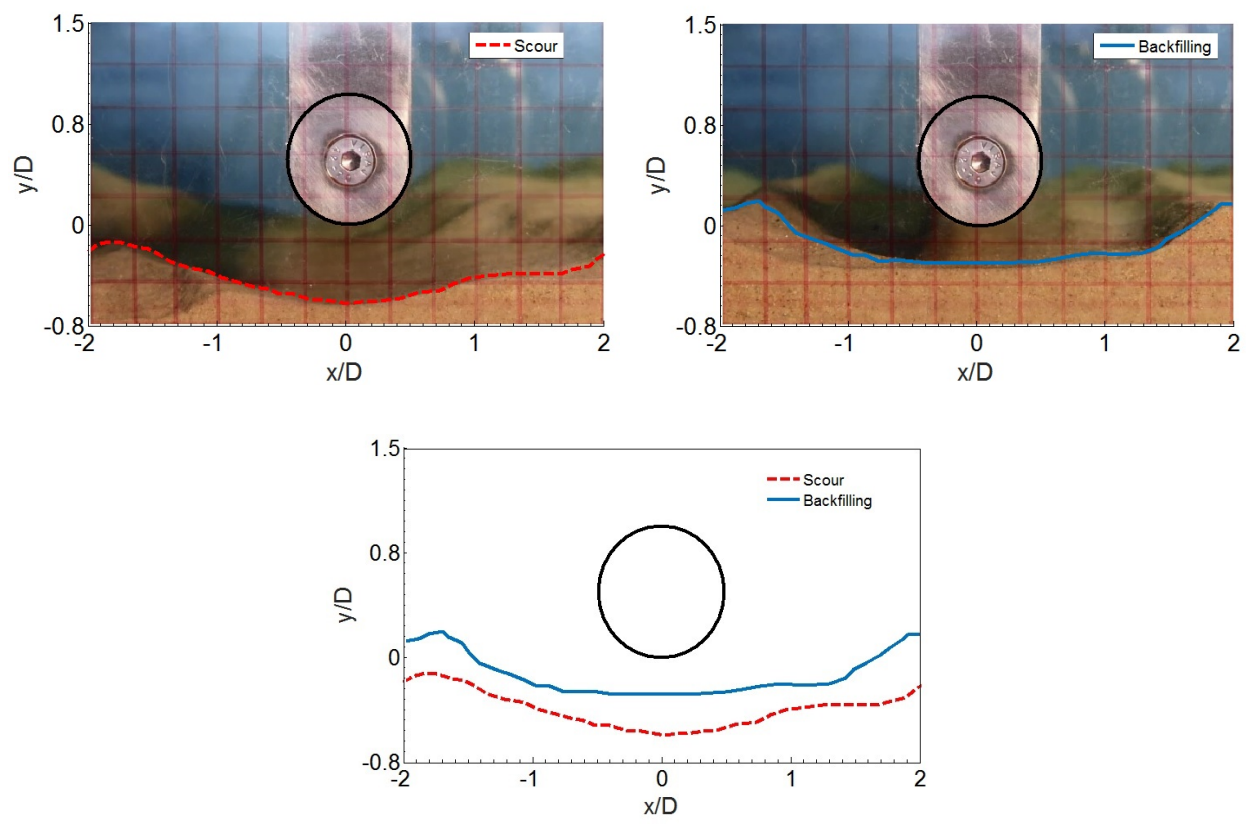

Figure 4: Snap shots of the scour profile near the pipeline during test $\mathrm{R} 9(K C=9.7$ and $\theta=0.195)$. The upper-left sub-plot depicts the profile at the end of the current-induced scour stage $(t=0)$, whereas the upper-right sub-plot depicts the profile at the end of the wave-induced backfilling $(t=60 \mathrm{~min})$. The approximated profiles after the initial scour (dashed red line) and backfilling (solid blue line) are directly compared on the bottom sub-plot.

\subsubsection{Equilibrium scour depths}

As an initial check of the present results, we will first investigate if the observed equilibrium scour depths $\left(S_{0}\right.$ and $\left.S_{f}\right)$ are in line with previous observations. For this purpose, the experimentally determined equilibrium scour depths from current-induced scour $S_{0}$, as well as from wave-induced backfilling $S_{f}$ (as listed in Tables 1 and 2), are plotted in Figure 5. The wave-induced $S_{f} / D$ values are plotted versus their respective $K C$, whereas the current-induced $S_{0} / D$ values are plotted at the limit $K C=\infty$.

For comparison with the current-induced equilibrium scour depths $S_{0} / D$ (plus symbols), we also plot the (constant) regression equation from Sumer and Fredsøe (2002):

$$
\frac{S_{0}}{D}=0.6 \pm \sigma \quad \text { with } \quad \sigma=0.2
$$




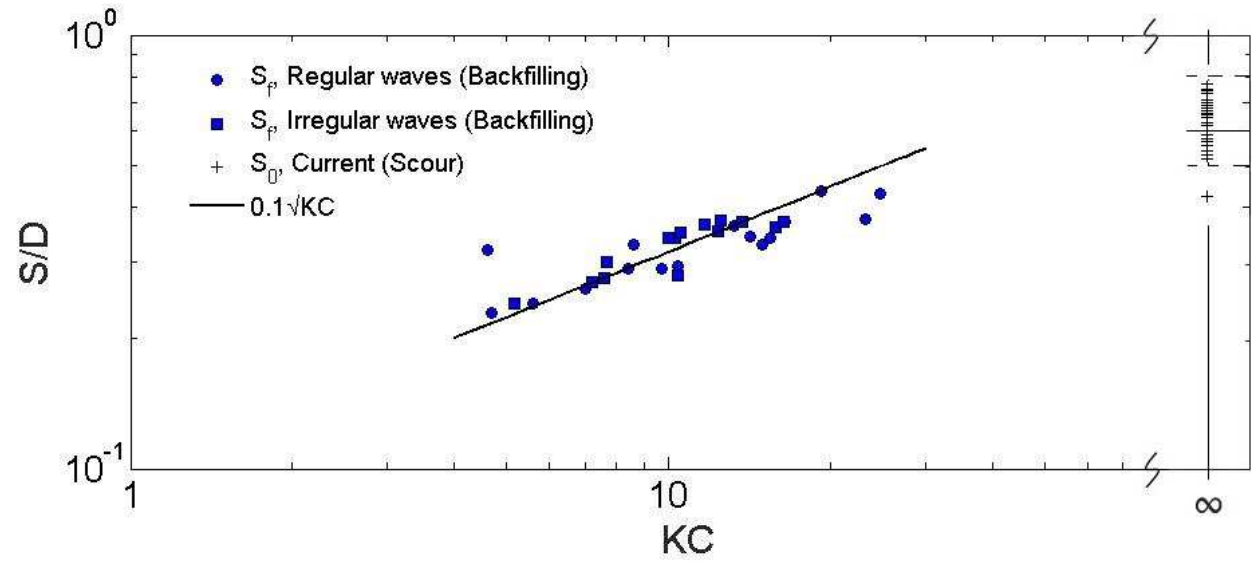

Figure 5: Measured equilibrium scour depths from the initial scour due to a current $\left(S_{0}\right.$, shown as plus symbols at $K C=\infty$ ), as well as from subsequent backfilling induced by regular (circles) and irregular (squares) waves $\left(S_{f}\right.$, plotted versus their respective $K C$ ). The horizontal solid line near $K C=\infty$ represents the regression equation (11) from Sumer and Fredsøe (2002), with the dashed lines indicating plus or minus the standard deviation; The diagonal solid line represents the regression equation (12) from Sumer and Fredsøe (1990).

where $\sigma$ is the standard deviation. The mean value $\left(S_{0} / D=0.6\right)$ is shown as the solid horizontal line towards the right side of this figure, with plus and minus the standard deviation shown as the two horizontal dashed lines. Here it is seen that the observed current-induced scour closely matches the target; All but one of the present measured $S_{0}$ values fall within one standard deviation of the expected mean, hence confirming that the current-induced equilibrium scour depths, here used as the initial conditions for backfilling, are: 1) reasonably constant and 2) in line with previous observations.

Similarly, the equilibrium scour depths obtained under wave-induced backfilling, $S_{f} / D$, are depicted versus their respective $K C$ values as the circles (regular waves) and squares (irregular waves) in Figure 5. These are likewise compared with the experimentally-based regression equation of Sumer and Fredsøe (1990):

$$
\frac{S}{D}=0.1 \sqrt{K C}
$$

shown as the diagonal solid line. This equation is based on the extensive laboratory data sets of Sumer and Fredsøe (1990) as well as Lucassen (1984), after recasting the latter in dimensionless terms. These data sets in total, cover 50 cases with a range of $2 \leq K C \leq 1050$ with pipeline di- 
ameters $1 \mathrm{~cm} \leq D \leq 18 \mathrm{~cm}$. As seen from Figure 5, the equilibrium scour depths formed under wave-induced backfilling are likewise in good agreement with Eq. (12). As expected, there is a clear tendency for the equilibrium scour depth to increase with $K C$. Note that greater scatter is observed in the present regular wave cases (circles) than in the irregular wave cases (squares). This is most likely related to small partial reflections that, with regular waves, will result in an organized pattern of partial standing waves. While we have attempted to minimize such effects, they cannot be eliminated entirely due to experimental limitations. Nevertheless, we feel that the present results generally support the overall findings of Fredsøe et al. (1992), who showed that the equilibrium scour depth under wave-induced backfilling was governed by the final $K C$. The present experimental findings further extend this conclusion from the wave-to-wave backfilling scenarios studied by Fredsøe et al. (1992), to also include to the current-to-wave backfilling scenarios considered herein.

\subsubsection{Backfilling time scale}

We will now turn our attention to the time scale of backfilling. For cases involving changes in pure wave climates, Fredsøe et al. (1992) found that the backfilling time scale was potentially governed by: (1) the KeuleganCarpenter number of the initial wave $K C_{0}$, which generates the initial scour hole $S_{0} / D ;(2)$ that of the subsequent wave $K C_{f}$, which backfills the scour hole to its final depth, $S_{f} / D$; and (3) the Shields parameter $\theta$ associated with the latter wave climate, which largely governs the sediment transport rate. Accordingly, on dimensional grounds, the non-dimensional time scale for so-called wave-to-wave backfilling scenarios can be represented e.g. as:

$$
T_{b}^{*}=f\left(K C_{0} \text { or } \frac{S_{0}}{D}, K C_{f} \text { or } \frac{S_{f}}{D}, \theta\right) .
$$

Due to the complexity (three parameter dependence), combined with a limited number of backfilling experiments, Fredsøe et al. (1992) did not propose a closed form expression for the backfilling time scale in wave-to-wave backfilling situations.

The present experimental program has intended to simplify the relatively complex situation considered above to its most elementary form via the use of current-induced scour holes as initial conditions. By exploiting that the initial scour depth $S_{0} / D$ can be taken as, more or less, uniform (as indicated e.g. by the constant regression Eq. (11), which is again matched well by the current scour values depicted in Figure 5) we may eliminate the first 
argument in Eq. (13); By then setting $K C_{f}=K C$, we simplify (13) to

$$
T_{b}^{*}=f(K C, \theta),
$$

i.e. a function potentially involving two, rather than three, parameters. Note that the potential dependence on $K C$ and $\theta$ is identical to expectations for the scour time scale $T_{s}^{*}$ on purely dimensional grounds, see Fredsøe et al. (1992).

In an attempt to quantify the backfilling time scale for the present current-to-wave conditions, based on Eq. (14), the non-dimensional backfilling time scales $T_{b}^{*}$ are plotted versus their respective Shields parameters $\theta$ in Figure 6. Experimental results for backfilling under both regular (circles) and irregular waves (squares) are included. As seen, the results from

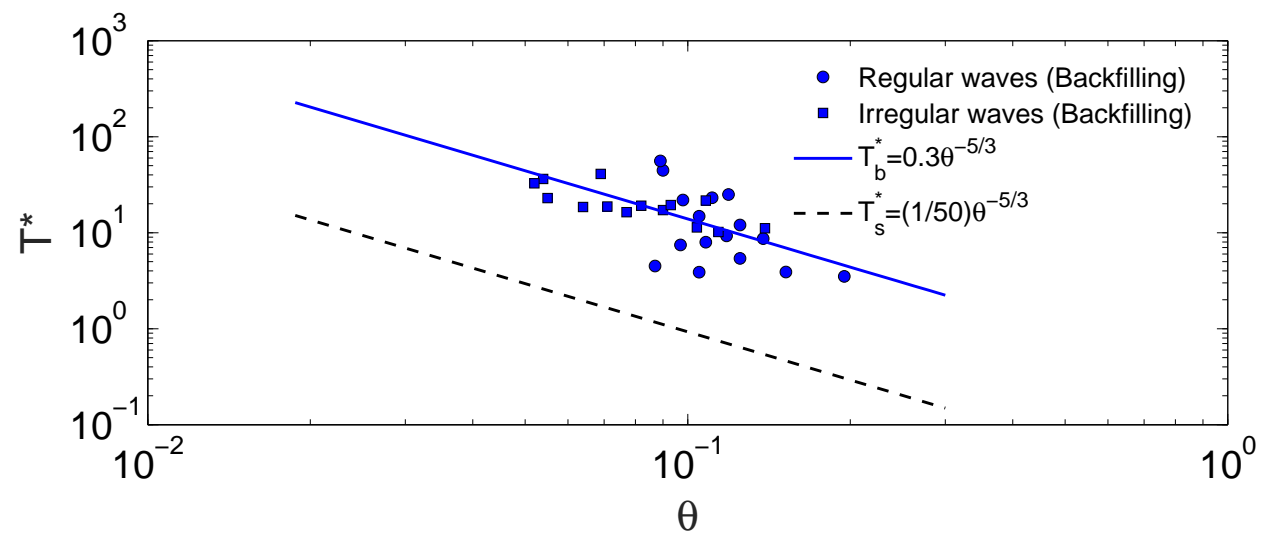

Figure 6: Measured non-dimensional backfilling time scales versus Shields parameter $\theta$ for regular (circles) and irregular (squares) waves. The solid blue line represents the regression equation (15); The dashed line additionally represents the regression equation (16) for the scour time scale (Fredsøe et al., 1992), which is included as a reference.

regular or irregular waves cluster similarly, and are reasonably represented by the regression equation:

$$
T_{b}^{*}=0.3 \theta^{-5 / 3}, \quad K C \leq 25 .
$$

It can be noted that many of the points scattered above this line correspond to cases where the observed initial backfilling time series is nearly flat (e.g. Cases R10 and R11 in Figure 2); In such cases the initial profile morphology following introduction of the waves was more dominated by sediment re-distribution, prior to eventual reduction of the scour depth 
beneath the pipeline. Also shown on Figure 6 as the dashed line is the experimentally-based scour time scale proposed by Fredsøe et al. (1992):

$$
T_{s}^{*}=\frac{1}{50} \theta^{-5 / 3}=0.02 \theta^{-5 / 3} .
$$

It is emphasized that this line serves as a reference rather than a target. By comparing the present data and Eq. (15) with Eq. (16) it is clear that the time scale of backfilling, while sharing approximately the same dependence on $\theta$, exceeds that of scour by a full order of magnitude. This is qualitatively consistent with prior findings from other backfilling studies, e.g. Fredsøe et al. (1992), Fuhrman et al. (2014), Zhang et al. (2016), Sumer et al. (2013), who have all generally found that the backfilling process is slower than that of scour. To the authors' knowledge, Eq. (15) is the first systematic quantification of the wave-induced backfilling time scale beneath submarine pipelines. It is emphasized that it is strictly valid only under so-called current-to-wave backfilling scenarios, though its relation for more general wave-induced backfilling scenarios will be discussed in what follows.

As indicated in Eq. (14), there may also be additional dependence of the backfilling time scale on $K C$. To investigate this, inspired by Eq. (15), we plot $T^{*} / \theta^{-5 / 3}=T^{*} \theta^{5 / 3}$ versus $K C$ in Figure 7 , with the lead constant 0.3 now shown as the horizontal line. As can be seen in Figure 7 the experimental data are essentially scattered around this constant line, hence no additional dependence of $T_{b}^{*}$ on $K C$ can be determined from the present data set. Interestingly, the lack of $K C$ dependence on the backfilling time

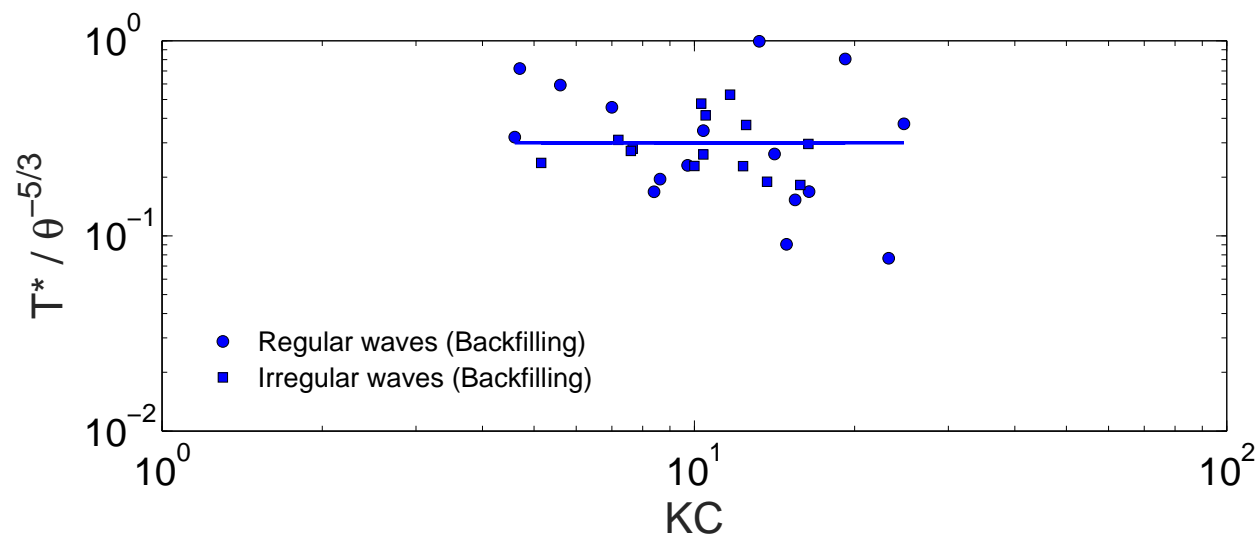

Figure 7: A plot showing measured $T^{*} / \theta^{-5 / 3}=T^{*} \theta^{5 / 3}$ versus $K C$ from the present backfilling experiments involving regular (circles) and irregular (squares) waves. The horizontal blue line shows the constant 0.3 from the regression equation (15). 
scale mirrors similar findings of Fredsøe et al. (1992) for the scour time scale, leading to Eq. (16). Sumer and Fredsøe (2002) explained this as due to the time scale being dominated by tunnel erosion at the onset of scour. It is less clear why $K C$ would not affect the backfilling time scale significantly; If anything, one might have expected a decreasing trend with $K C$ i.e. shorter backfill times as the expected final equilibrium scour depth is increased. In any event, the present results clearly suggest that $\theta$, which controls the rate of sediment transport, is again the most important parameter governing the backfilling time scale. Note that a similar investigation of the present data has likewise not found any discernible secondary dependence on $S_{0} / D$, though it is again emphasized that we have, by design, attempted to maintain this quantity as constant as possible.

\subsection{Comparison with wave-to-wave backfilling}

We will finally compare the regression curves above with the wave-towave backfilling experimental time scales from the study of Fredsøe et al. (1992). These are shown (red triangles) as a function of $\theta$ in Figure 8. Here

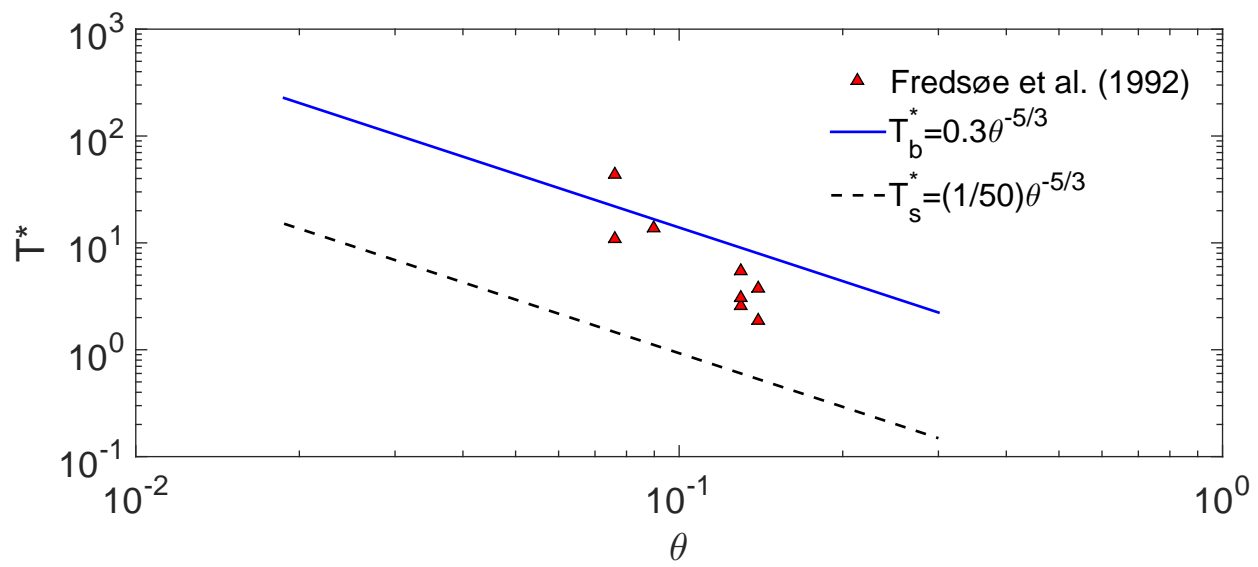

Figure 8: Comparison of the non-dimensional wave-to-wave backfilling time scales measured by Fredsøe et al. (1992) (red triangles) with the current-to-wave regression equation (15) (full line). The dashed line additionally depicts the reference scour time scale from Eq. (16), included as a reference.

it is seen that the wave-to-wave backfilling time scales, while being considerably larger than $T_{s}$ (dashed line), are generally less than found during the present study (full line); The lone exception corresponds to a case where the initial wave-induced scour (prior to backfilling) was large, $S_{0} / D=0.58$, which is quite close to that expected from pure currents, Eq. (11), as used 
herein. The reduced $T_{b}^{*}$ values for wave-to-wave backfilling scenarios is as expected for two reasons: (1) current-induced scour holes tend to be larger than those produced by waves (at least for moderate $K C$ ), and (2) currentinduced scour holes are typically asymmetric, predominantly depositing potential backfill material to a single side. Thus, provided the initial scour is moderate (say $S_{0} / D \leq 0.6-0.8$, corresponding e.g. approximately to $K C \leq 36-64$ based on Eq. 12), Eq. (15) can likely be taken as a reasonable upper limit for the backfilling time scale for other wave-induced backfilling situations. No attempt will be made at directly parameterizing the time scale for other backfilling scenarios in the present work, however.

\section{Numerical Simulations}

\subsection{Model description and set-up}

To complement the previously-described experimental campaign, we will now test the ability of an existing fully-coupled hydrodynamic and morphological numerical model to simulate current-to-wave-induced backfilling, as studied experimentally in the preceding section. The model is based on incompressible Reynolds-averaged Navier-Stokes (RANS) equations, coupled with $k-\omega$ turbulence closure, with additional bed and suspended load descriptions forming the basis for seabed morphology, as originally developed and described by Jacobsen et al. (2014). The model has been extensively validated on several scour-related problems, including wave-induced scour and backfilling beneath pipelines by Fuhrman et al. (2014), current- and combined wave-plus-current induced scour beneath pipelines by Larsen et al. (2016), as well as 3D current-induced flow and scour around a monopile by Baykal et al. (2015). The model is implemented within the open-source CFD toolbox OpenFOAM, version 1.6-ext, making use of finite volume spacial discretizations. For brevity the model will not be re-described here; For further details the reader is referred to Jacobsen et al. (2014) as well as the other references immediately above.

In line with the previously discussed experimental protocol, the initial bed profile used for forthcoming backfilling simulations stems directly from a simulated current-generated scour hole with the same model, as described in Larsen (2015) and Larsen et al. (2016); More specifically, the initial profile is taken directly from a case considered by Larsen (2015), his Fig. 3.7.5, in which $U_{f}=2.1 \mathrm{~cm} / \mathrm{s}$ and $\theta=0.143$; This initial profile is depicted in Figure 9. This case results in a simulated equilibrium scour depth of $S_{0} / D=0.789$, which is reasonably in line with the previously described experiments, as well as Eq. (11). The pipeline utilized in the simulations has 
the same diameter as in the experiments $(D=0.03 \mathrm{~m})$, and the sediment characteristics $(d=0.19 \mathrm{~mm}, s=2.65)$ are likewise very similar. Each simulation uses a computational mesh spanning $-20 D \leq x \leq 20 D$ with a total horizontal span of $40 D$ and with a domain height of $10 D$, as in the previous simulations of Fuhrman et al. (2014).

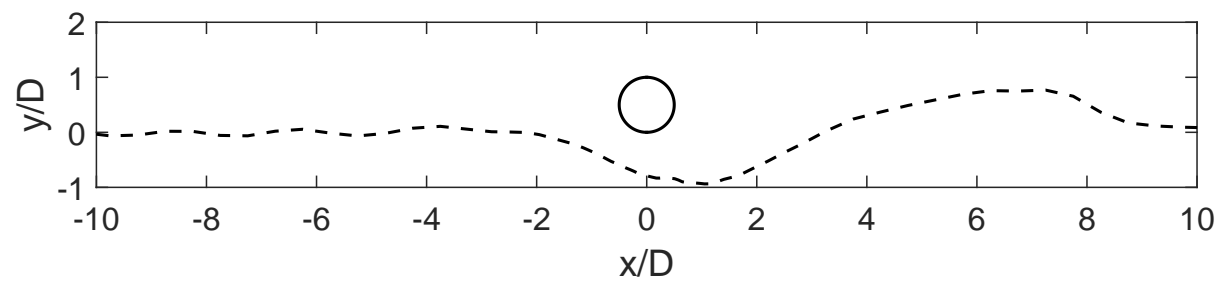

Figure 9: Computed scoured bed profile due to a current, used as initial conditions for wave-induced backfilling simulations.

The numerical simulations will only consider backfilling due to regular wave signals. Within the model an oscillatory (sinusoidal) flow is driven by a specified velocity at the left-hand inlet boundary, which stems from a separate one-dimensional-vertical pure wave boundary layer simulation (using the same model), as described by Larsen et al. (2016). The model described above is utilized to study backfilling induced by the 12 different wave climates listed in Table 3 , having $5 \leq K C \leq 30$ and $0.07 \leq \theta \leq 0.2$. As seen, the range of governing parameters is similar to those utilized in the preceding experiments. Individual simulations are monitored and stopped when an apparent new equilibrium is reached. The simulated current-to-wave induced backfilling processes are long and computationally expensive, with each run requiring simulations times of $O$ (months) on a single processor.

\subsection{Backfilling time series and bed profiles}

As typical examples, selected time series of the simulated scour depths during the wave-induced backfilling process are presented in Figure 10. Comparison of the initial (dashed lines) and final backfilled scour profiles (full lines) are likewise presented Fig. 11. For each simulation, the final equilibrium scour depths are calculated by taking the average over the final 10 simulated periods. Based on the time series of scour depth, non-dimensional backfilling time scales $T_{b}^{*}$ have likewise been calculated via integration, in precisely the same fashion as in the preceding experiments. The final values 
Table 3: Summary of simulated cases involving wave-induced backfilling of a currentgenerated scour hole.

\begin{tabular}{ccccccc}
\hline$K C$ & $T_{w}(\mathrm{~s})$ & $U_{m}(\mathrm{~cm} / \mathrm{s})$ & $U_{f m}(\mathrm{~cm} / \mathrm{s})$ & $\theta$ & $S_{f} / D$ & $T_{b}^{*}$ \\
\hline 5 & 0.87 & 17.2 & 2.15 & 0.15 & 0.19 & 12.0 \\
5 & 0.72 & 20.8 & 2.48 & 0.20 & 0.22 & 8.67 \\
10 & 1.81 & 16.5 & 1.75 & 0.10 & 0.31 & 22.7 \\
15 & 3.02 & 14.9 & 1.47 & 0.07 & 0.38 & 11.4 \\
15 & 2.38 & 18.9 & 1.75 & 0.10 & 0.41 & 14.7 \\
15 & 2.05 & 22.0 & 1.96 & 0.125 & 0.39 & 7.75 \\
15 & 1.81 & 24.8 & 2.15 & 0.15 & 0.39 & 6.67 \\
20 & 3.65 & 16.4 & 1.47 & 0.07 & 0.45 & 10.2 \\
20 & 1.95 & 30.8 & 2.48 & 0.20 & 0.44 & 7.11 \\
25 & 3.34 & 22.4 & 1.75 & 0.10 & 0.50 & 27.0 \\
25 & 2.95 & 25.4 & 1.96 & 0.125 & 0.52 & 7.27 \\
30 & 3.84 & 23.5 & 1.75 & 0.10 & 0.55 & 16.0 \\
\hline
\end{tabular}

for both $T_{b}^{*}$ and $S_{f} / D$ are listed in Table 3 . These will be analyzed further in what follows.

\subsection{Equilibrium scour depths}

As in the preceding experiments, we begin our comparisons by checking if the computed wave-induced (backfilling) equilibrium scour depths are in line with expectations. As a preliminary check, for each of the time series depicted in Figure 10 a horizontal dashed line corresponding to the target equilibrium scour depth predicted by the regression equation of Sumer and Fredsøe (1990), Eq. (12), has been added. As seen in these examples, the model typically backfills to the expected scour depth corresponding to the new wave climate, generally in accordance with the preceding current-towave backfilling experiments (Figure 5), as well as in previous experimental (Fredsøe et al., 1992) and numerical (Fuhrman et al., 2014) works studying wave-to-wave backfilling beneath submarine pipelines. This is further demonstrated in Figure 12, which depicts the computed $S_{f} / D$ values (open circles) versus $K C$ for all of the simulations considered. For comparison the experimentally obtained equilibrium scour depths (both for regular and irregular waves) from Figure 5 are also displayed. As can be seen, both experimental (as previously shown), as well as all numerical results match the regression equation Eq. (12) quite closely. 


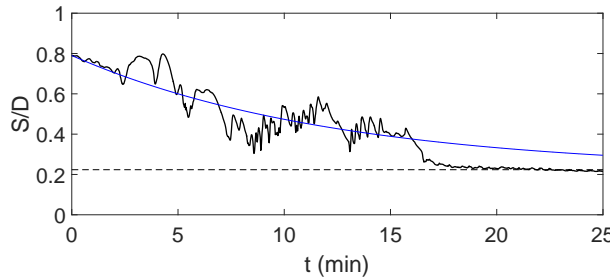

(a) $K C=5$ and $\theta=0.2$

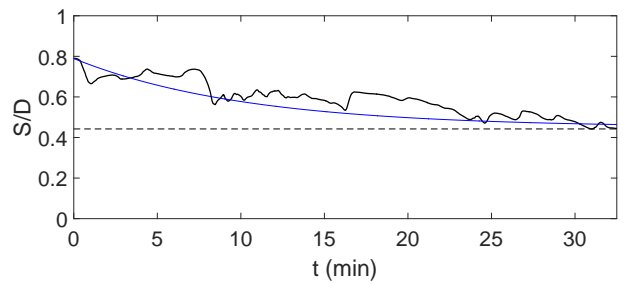

(c) $K C=20$ and $\theta=0.07$

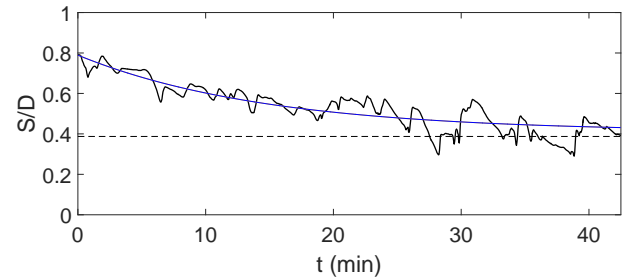

(b) $K C=15$ and $\theta=0.1$

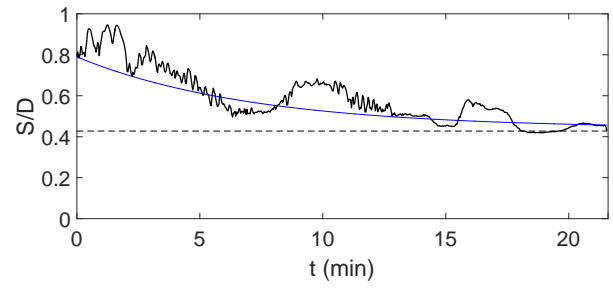

(d) $K C=20$ and $\theta=0.2$

Figure 10: Selected examples showing computed scour depth time series from waveinduced backfilling simulations. The dashed lines indicate the equilibrium scour depth predicted by Eq. (12).

\subsection{Non-dimensional time scale}

As a final check of the simulated results, the non-dimensional backfilling time scales $T_{b}^{*}$ (open circles) are plotted versus their respective Shields parameters $\theta$ in Figure 13. Again, for comparative purposes, the experimentally obtained values from Figure 6 are also displayed, as are the reference scour time scale (dashed line, Eq. 16) and target backfilling time scale (full line, Eq. 15) regression curves. It can be noted that simulated scour time scales from the present model have previously been demonstrated to be accurate by Fuhrman et al. (2014) for waves and by Larsen et al. (2016) for currents. From Figure 13, despite scatter in the results, the simulated backfilling time scales are again clearly an order of magnitude larger than would be expected for scour, consistent with our experimental findings. Although the number of cases simulated is limited, and the precise $\theta^{-5 / 3}$ dependence could not have been derived based on the numerical results alone, the backfilling simulations agree reasonably with the experimentally-based backfilling time scale regression equation, Eq. (15). Overall and collectively, the numerical results hence support the most important findings based on the previously presented experimental campaign regarding the equilibrium scour depths and magnitude of the backfilling time scale. 


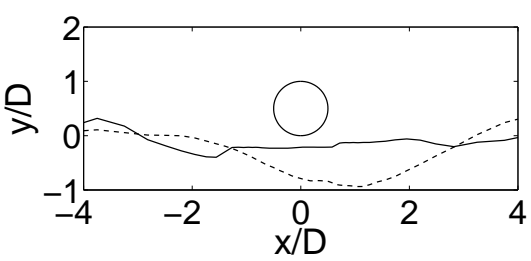

(a) $K C=5$ and $\theta=0.2$

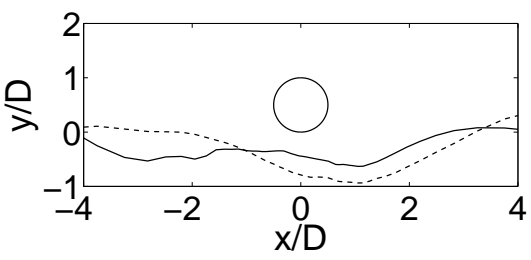

(c) $K C=20$ and $\theta=0.07$

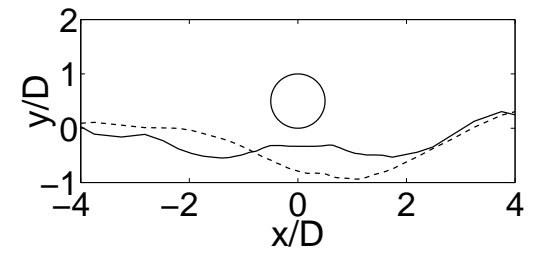

(b) $K C=15$ and $\theta=0.1$

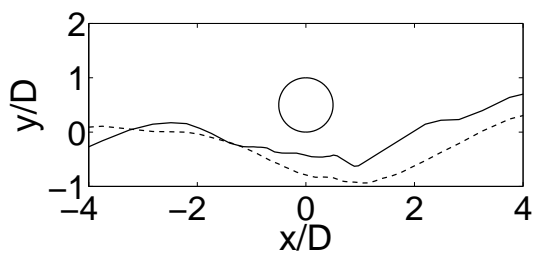

(d) $K C=20$ and $\theta=0.2$

Figure 11: Selected examples showing computed scour profiles from simulated waveinduced backfilling (full lines) after an equilibrium scour depth has been reached. The dashed lines indicate the current-induced scour profile used as the initial condition, from Figure 9 .

\section{Conclusions}

The present paper has experimentally investigated wave-induced backfilling processes beneath submarine pipelines, following initial scouring due to a steady current (so-called current-to-wave backfilling scenarios). Backfilling induced by both regular and irregular waves has been considered, with both yielding similar results. The results demonstrate that the initially scoured profile will backfill to a new equilibrium scour depth governed by the new wave climate, generally consistent with previous experimental (Fredsøe et al., 1992) and numerical (Fuhrman et al., 2014) results involving wave-to-wave backfilling scenarios.

Making use of video camera recordings, the time series of the scour depth for each experiment has been obtained and analyzed, yielding corresponding backfilling time scales via integration. For the first time the (current-towave) backfilling time scale for submarine pipelines has been quantified in terms of the governing Shields parameter, leading to the regression equation: $T_{b}^{*}=0.3 \theta^{-5 / 3}$, presented as Eq. (15) within the paper. Importantly, this is a full order of magnitude larger than for the corresponding well-known scour time scale. No additional dependence of the backfilling time scale on the Keulegan-Carpenter number has been detected from the present data set. While the new expression is strictly valid only for current-to-wave backfilling 


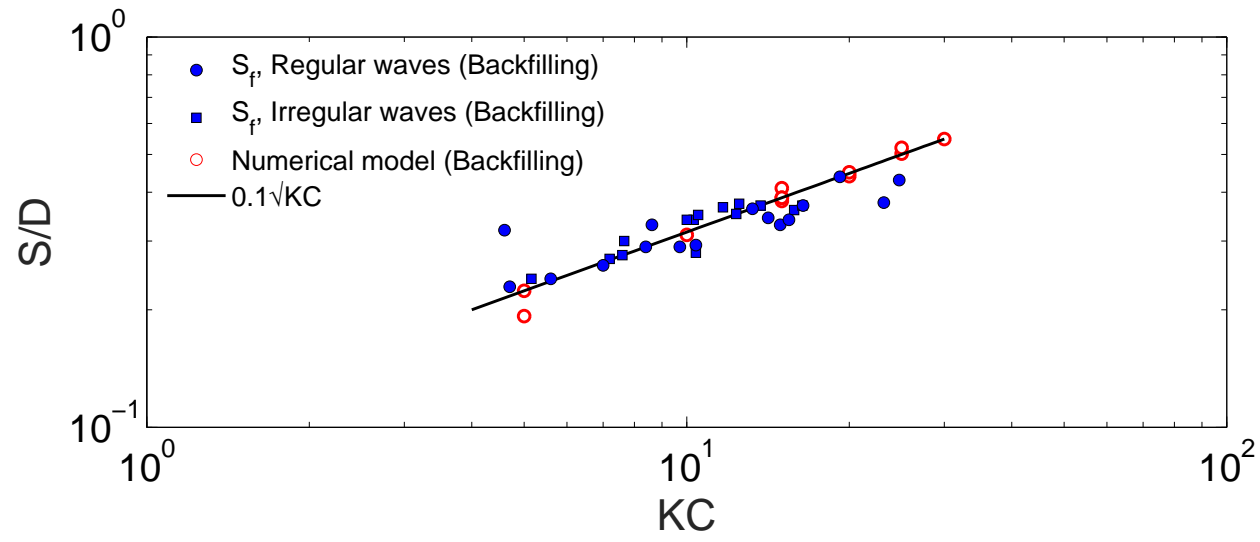

Figure 12: Comparison of measured (closed symbols) and computed (open circles) equilibrium scour depths $S_{f}$ versus $K C$ for the current-to-wave backfilling cases considered herein. The solid line additionally depicts the regression equation (12) from Sumer and Fredsøe (1990).

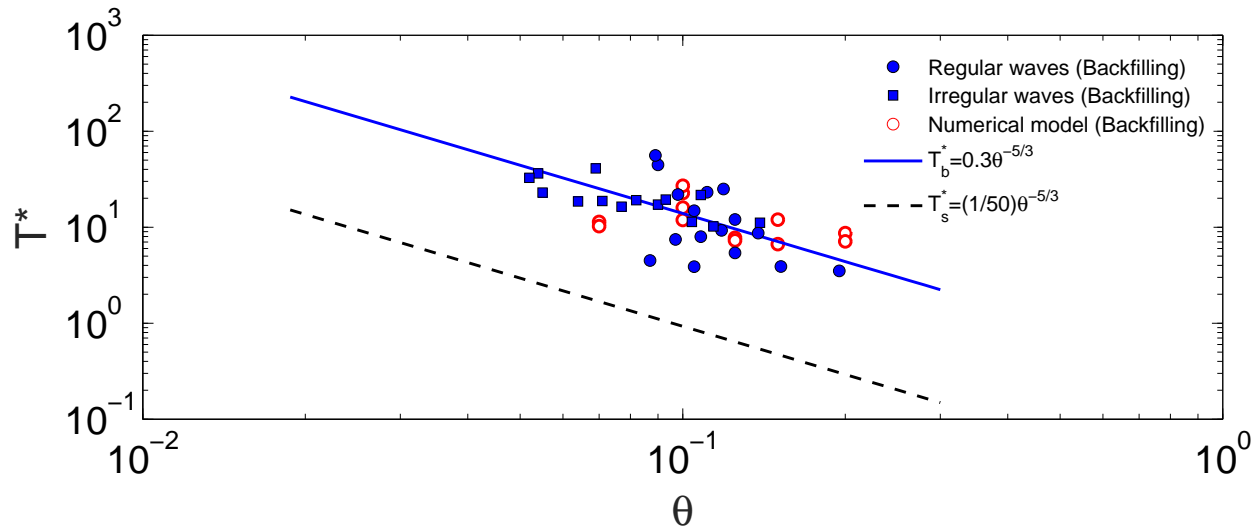

Figure 13: Comparison of measured (closed symbols) and computed (open circles) nondimensional backfilling time scales versus Shields parameter $\theta$. The solid blue line represents the regression equation (15); The dashed line additionally represents the regression equation (16) for the scour time scale (Fredsøe et al., 1992), which is included as a reference. 
scenarios, comparison with previously measured wave-to-wave backfilling time scales (Fredsøe et al., 1992) suggests that it can likely be taken as an upper limit for more general wave-induced backfilling situations, provided that the initial (pre-backfilling) scour depth does not exceed that expected from a pure current (approximately $S_{0} / D=0.6-0.8$ ).

The experimental campaign has additionally been complemented with similar numerical simulations (using regular waves), based on a fully-coupled hydrodynamic and morphodynamic CFD model (Jacobsen et al., 2014), extending previous pipeline scour-related applications of Fuhrman et al. (2014) and Larsen et al. (2016). Comparison of the numerical and experimental results demonstrate the ability of the CFD model to reasonably simulate the current-to-wave backfilling process, both in terms of the achieved new waveinduced equilibrium scour depths as well as the corresponding backfilling time scales.

\section{Acknowledgments}

The first author acknowledges the support of a postdoctoral grant from The Scientific and Technical Research Council of Turkey (TUBITAK, grant no. 2219). The third and last authors additionally acknowledge support from the FP7-ENV-2013.604-3 European Union project ASTARTE (Assessment, STrategy And Risk Reduction for Tsunamis in Europe), grant no. 603839.

\section{References}

Baykal, C., Sumer, B. M., Fuhrman, D. R., Jacobsen, N. G., Fredsøe, J., 2015. Numerical investigation of flow and scour around a vertical circular cylinder. Phil. Trans. Roy. Soc. A 373, article no. 20140104.

Brørs, B., 1999. Numerical modeling of flow and scour at pipelines. J. Hydraul. Eng. ASCE 125, 511-523.

Fredsøe, J., Deigaard, R., 1992. Mechanics of Coastal Sediment Transport. World Scientific, Singapore.

Fredsøe, J., Sumer, B. M., Arnskov, M. M., 1992. Time scale for wave/current scour below pipelines. Int. J. Offshore Polar Eng. 2, 13-17.

Fuhrman, D. R., Baykal, C., Sumer, B. M., Jacobsen, N. G., Fredsøe, J., 2014. Numerical simulation of wave-induced scour and backfilling processes beneath submarine pipelines. Coastal Engineering 94, 10-22. 
Fuhrman, D. R., Schløer, S., Sterner, J., 2013. RANS-based simulation of turbulent wave boundary layer and sheet-flow sediment transport processes. Coast. Eng. 73, 151-166.

Jacobsen, N. G., Fredsøe, J., Jensen, J. H., 2014. Formation and development of a breaker bar under regular waves. Part 1: Model description and hydrodynamics. Coast. Eng. 88, 182-193.

Kazeminezhad, M. H., Yeganeh-Bakhtiary, A., Etemad-Shahidi, A., Baas, J. H., 2012. Two-phase simulation of wave-induced tunnel scour beneath marine pipelines. J. Hydraul. Eng. ASCE 138, 517-529.

Kozakiewicz, A., Sumer, B., Fredsøe, J., 1994. Cross flow vibrations of cylinder in irregular oscillatory flow. J. Waterway, Port, Coastal, Ocean Eng. $120: 6,515-534$.

Larsen, B. E., 2015. Simulation of wave plus current induced scour and backfilling beneath pipelines. MSc thesis, Technical University of Denmark.

Larsen, B. E., Fuhrman, D. R., Sumer, B. M., 2016. Simulation of waveplus-current induced scour beneath submarine pipelines. J. Waterw. Port Coast. Ocean Eng.-ASCE, article no. 04016003.

Leckie, S. H. F., Mohr, H., Draper, S., McLean, D. L., White, D. J., Cheng, L., 2016. Sedimentation-induced burial of subsea pipelines: Observations from field data and laboratory experiments. Coast. Eng. 114, 137-158.

Liang, D., Cheng, L., 2005. Numerical modeling of flow and scour below a pipeline in currents Part I. Flow simulation. Coast. Eng. 52, 25-42.

Lucassen, R. J., 1984. Scour underneath submarine pipelines, Report No. PL-4 2A, Netherlands Marine Tech. Res., Netherlands Industrial Council for Oceanology, Delft University of Technology, Delft, The Netherlands.

Schäffer, H. A., Stolborg, T., Hylledted, P., 1994. Simultaneous generation and active wave absorption of waves in flumes. In: Proc. Int. Symp. Waves Phys. Numer. Model. Vancouver,Canada, pp. 90-99.

Sumer, B. M., Fredsøe, J., 1990. Scour below pipelines in waves. J. Waterw. Port Coast. Ocean Eng.-ASCE 116, 307-323.

Sumer, B. M., Fredsøe, J., 2000. Experimental study of 2d scour and its protection at a rubble-mound breakwater. Coastal Engineering 40 (1), 59-87. 
Sumer, B. M., Fredsøe, J., 2002. The Mechanics of Scour in the Marine Environment. World Scientific, Singapore.

Sumer, B. M., Petersen, T. U., Locatelli, L., Fredsøe, J., Musumeci, R. E., Foti, E., 2013. Backfilling of a scour hole around a pile in waves and currents. J. Waterw. Port Coast. Ocean Eng.-ASCE 139, 9-23.

Zanganeh, M., Yeganeh-Bakhtiary, A., Wahab, A. K. A., 2012. Lagrangian coupling two-phase flow model to simulate current-induced scour beneath marine pipelines $38,64-73$.

Zhang, Q., Draper, S., Cheng, L., An, H., 2016. Scour below a subsea pipeline in time varying flow conditions. Applied Ocean Research 55, 151 $-162$. 